\title{
A New Equilibrium Strategy of Supply and Demand for the Supply Chain of Pig Cycle
}

\author{
Changxiang Lu $\left(\mathbb{D}\right.$, Jiaqi Fang ${ }^{(D)}$, and Shaochuan Fu \\ School of Economics and Management, Beijing Jiaotong University, Beijing100000, China \\ Correspondence should be addressed to Shaochuan Fu; shchfu@bjtu.edu.cn
}

Received 14 May 2020; Revised 2 August 2020; Accepted 5 August 2020; Published 2 September 2020

Guest Editor: Shib Sankar Sana

Copyright (c) 2020 Changxiang Lu et al. This is an open access article distributed under the Creative Commons Attribution License, which permits unrestricted use, distribution, and reproduction in any medium, provided the original work is properly cited.

The pig market had experienced a cycle of price rise and fall, also known as the "pig cycle." This paper analyzes the fluctuation relationship between pig price, pig supply, and pork demand, constructs a system dynamics model of the pig industry by decomposing the structure of the pig supply chain, and then discusses the causes of "pig cycle," as well as the supply chain management strategy and industrial policy, to stabilize the pig industry market. Research shows that reducing the cost of pig breeding, countercyclical adjustment, and government macrocontrol can effectively reduce the fluctuation of pig prices. Among them, reducing the pig breeding cost is the most effective long-term strategy to stabilize the pig price.

\section{Introduction}

China is the world's largest producer and consumer of pork, consuming approximately 700 million live pigs each year. During this process, the price of live pigs in China had experienced huge fluctuations. In 2018, scholars pointed out that the profit-seeking behavior of live pig farmers caused fluctuations in live pig prices and caused environmental pollution. The government immediately introduced a "decapacity" policy for individual farmers to withdraw from pig breeding. The African swine fever epidemic caused a sharp drop in the number of live pigs in China in 2019, and then the price of live pigs reached a record high of $6 \mathrm{USD} / \mathrm{kg}$. Due to the high price of live pigs and rising of CPI, consumers suffered losses. Once the production capacity was restored, the price of live pigs fell sharply again, which caused losses to the pig breeding companies. Therefore, in order to maximize the benefits of the supply chain, it is necessary to study the reasons of the pig cycle and the strategies of stabilizing the price of pigs.

Regular cyclical changes are often observed in the prices and production of agricultural products. In the 1920s, scholars observed the vibration law of pig price, which is called the "pig cycle" (Coase and Fowler [1,2]). Larry and Limothy [3] investigated the development of the pig industry in the United States from 1940 to 1990 and found that the average period of the "pig cycle" was 4.08 years, and its fluctuation range was 2 to 6 years. The traditional pig cycle is 4 years (Dawson [4]; Sterman [5]). There are also cycles existing in other breeding industries, such as the "cow cycle," which is generally $10-12$ years (Huang [6]).

The classic economic theory about the commodity cycle is "cobweb theory" (Ezekiel [7]; Harlow [8]; Talpaz [9]). Cobweb theory is a theoretical tool, which is used to explain the cycle caused by production lag response. Harlow perfected the simple cobweb model from the four supply factors of sow number, slaughtered pig number, the effect of beef, and other substitutes on the pork price. Waugh [10] solved the influence of nonlinear and multi-input factors on functions. By introducing the concept of the multidimensional cobweb model, Waugh solved the problem of the influence of other factors pointed out by the pig price on production decisions.

The traditional cobweb model has two assumptions: the supply and demand functions are linear; the supply and demand of each phase are balanced. Therefore, scholars also pointed out that the "cobweb model" is not suitable for serious simulation of market dynamics (Sterman [5]).

Because the cobweb model does not consider the stock flow structure and assumes that the commodity cycle is twice 
the production delay, the pig cycle is much more than twice the production delay (McClements [11]). For example, the breeding cycle of live pigs is about 11 months, while the pig cycle is about 4 years. Besides, spectral analysis (Slade [12]) and harmonic motion models (McClements [11]) are also commonly used.

Scholars have also analyzed the causes of the pig cycle. In economics, it is believed that cycles result from delayed responses to changes in prices and other variables. Haas and Ezekiel [13] described the relationship between pig price and corn price with a linear model. Harlow [8] speculated that the pig cycle may be internal to the industry rather than the result of delayed response to external influences. According to the classification of internal and external influencing factors, it can be roughly divided into internal transmission mechanisms (such as supply and demand laws and pig breeding cycle) and external impact mechanisms (such as epidemic, macrocontrol, and consumption habits).

In the market economy, price is at the core of adjusting the balance between supply and demand. The quantity and value of goods in past periods determine the quantity and value of goods in subsequent periods. Due to the long delay in the response of supply to price changes, the effect of competition game and bounded rationality (Simon [14]) and supply and demand is out of balance, and then a business cycle occurs. Accordingly, this paper constructs a system dynamics model of pig supply chain from three aspects: pig price, pork demand, and pork supply.

System dynamics was found by Professor Jay Forrester of MIT in the 1950s. John Sterman, a professor at MIT and currently director of the MIT Institute of System Dynamics, expanded it into a business dynamic analysis method and had widely used in commodity market analysis (Berg and Huffaker [15]). The application of dynamics in biology and mathematics has resulted in population dynamics and evolutionary dynamics.

This paper tries to answer the following two questions:

(1) Is the pig cycle caused by the interaction of pig prices, pig supply, and pork demand? How do the three influence each other?

(2) Which supply chain management strategies can stabilize the pig cycle? What is its role?

The novel contributions of this paper are as follows:

(1) Most scholars study the pig cycle coping strategies of a certain company or part of the pig supply chain participants from the microlevel, while this article through the macrolevel, to construct a more comprehensive pig supply chain system dynamics model, which can be viewed from a macroperspective and observe the reactions of participants in the pig supply chain

(2) This paper studies the impact of pig supply chain management strategies such as reducing pig breeding cost, countercyclical adjustments, and government macrocontrol on stabilizing the pig cycle and then constructs a model for simulation as well as quantitative analysis

\section{Literature Review}

There are three streams of literature that are closely related to our work: (1) live pig price; (2) pork supply and demand; and (3) supply chain coordination.

2.1. Live Pig Price. Tversky and Kahneman [16] found that the price of live pigs is constrained by historical prices with strong inertia. Bessler and Brandt [17] believed that the expectation of live pig prices is greatly affected by recent prices, while the impact on historical prices more than one year is small. Behavioral economics shows that people will make the linear speculative analysis of the recent situation and then use it to imagine future trends (Rostow [18]).

Kahneman and Tversky [19] created the anchoring and adjustment method. This method estimates the adjustment by reviewing known reference points (anchor points); then, decision makers use mental simulations to estimate significant or vague influence factors. Nerlove [20] and Marcet and Sargent [21] showed that the expected value of the explanatory variable will satisfy the adaptive adjustment process. Gerlow et al. [22] believed that the balance of supply and demand and unit breeding cost are the decisive factors that affect the price of live pigs. Tan and Zapata [23] believed that the pig breeding cost in Europe and America is much lower than China, which is the main reason for the relatively stable pig prices in Europe and the United States. Breimyer [24] believed that live pigs are the largest and most adjustable consumer of corn, so the price of live pigs is affected by corn supply and price changes. Shun et al. [25] conducted an empirical analysis of the influencing factors of pork price fluctuation in China. The analysis shows that pork price is greatly influenced by itself. The above research shows that the price of live pigs is affected by historical pig price, as well as the cost of pig breeding and the balance of supply and demand. These studies laid the foundation for the construction of a pig price model in this article.

2.2. Pork Demand and Supply. Norris [26] believed that consumption was mainly influenced by income, price, and consumption preferences. According to economic principles, substitutes such as mutton, beef, poultry, and fish will also affect pig consumption. Qi [27] calculated that the impact coefficient of pork and the substitutes is only 0.15 , indicating that substitutes have little impact on pork consumption. When the residents' income reaches a higher level, the increase in income does not significantly change the consumption of pork. He et al. [28] calculated the crossprice elasticity of pork and other five substitutes; the research found that the cross-price elasticity was almost zero. According to the prospect theory, the Heiner model, and the Simon model, the transaction parties do not expect to maximize their interests, but are "satisfied" (Heiner [29]). Pennings and Smidts's research [30] on the Dutch pig market also showed that when making risk decisions, using a measurement method based on the expected utility model has a better behavioral prediction effect. The complexity of the details causes people to pay too much attention to their 
own business and ignore the plans of others, which leads to the phenomenon of "competitive neglect," which makes the behavior of farmers consistent (Kahneman [31]). Through the regression analysis of the agricultural output and price changes, Bean [32] found that equilibrium prices usually lead to stable planting areas and livestock numbers. The above studies have conducted a detailed analysis of the factors affecting the supply and demand of live pigs.

2.3. Supply Chain Coordination. Bailey [33] believed that countercyclical adjustment can effectively increase profits and reduce losses. Hayes and Schmitz [34] pointed out that if the business cycle exists, the shrewd producers will take countercyclical adjustment to obtain high profits and avoid losses, while the poorly run producers will be eliminated. When more people take countercyclical adjustments, the business cycle will disappear. He and Zhao $[35,36]$ showed that, in the face of supply chain uncertainty, contracts can achieve flexible benefit distribution and effectively stabilize supply chain fluctuations. Modak and Kelle [37] also believed that shared revenue contracts can effectively resolve channel conflicts and then achieve higher profit margins. Modak et al. [38] analyzed the profit distribution and channel conflicts of the two-level supply chain. The analysis reveals that the subgame perfect equilibrium retail price cuts out the channel conflict and ensure the stability of the supply chain. In order to solve the coping problems of supply chain participants when demand is uncertain, Modak and Kelle [39] studied the Nash game problem between retailers and manufacturers, and they solved the equilibrium point of cooperation between the two parties. He et al. [40] demonstrated the role of government subsidies in the supply chain performance. Research has shown that government subsidies are always beneficial to consumers and then improve the performance of the entire supply chain. The government can also release meat reserves to subsidize consumers, but this policy also has drawbacks. Long-term storage of pork may result in quality degradation and high inventory holding costs (Sana et al. [41]). The storage, distribution, and market issues in the food supply chain have also caused extensive discussions among scholars (He et al [42]). We should also emphasize the importance of corporate social responsibility to prevent some companies from hoarding goods and driving up prices (Modak and Kelle [37]). The above research lays the foundation for the coordination research of the supply chain in this article.

\section{Problem Description and Modeling}

The basic assumptions of the system dynamics model of the pig supply chain are as follows:

(1) Political and economic stability: the pig breeding environment is stable, free from major diseases and disasters

(2) Stable behavioral preferences, including the stability of supply chain participants and the stability of consumer consumption
(3) Every link in the pig supply chain is considered as a whole

3.1. Pig Price Influencing Factors' Analysis. Price modeling is the most difficult part of economic modeling. In some papers, it is unreasonable to adjust the balance of supply and demand around the balanced price of live pigs. The market does not know the true supply curve and demand curve, so the equilibrium price cannot be assumed by calculating the average price of live pigs. Market decision makers can only adjust prices through trial and error, gradually adjusting prices to equilibrium prices; the process is called mountain climbing. According to the anchor and adjustment principle, this paper constructed a pig breeding model, and the price function is constructed as

$$
P=P^{*} \times f_{1}\left(\operatorname{signal}_{1}\right) \times f_{2}\left(\operatorname{signal}_{2}\right), \ldots, f_{n}\left(\operatorname{signal}_{n}\right) .
$$

As the anchor point, the expected price $P^{*}$ will be adjusted to the historical price. We use adaptive expectations, such as exponential smoothing, to construct the expected price function. The signal in the formula represents various factors that affect the price of live pigs, such as supply and demand balance, unit cost, and other factors, to realize the price adjustment process.

As can be seen from Figure 1, since 2003, China's pig price has gone through four cycles: 2003.5-2006.5, 2006.5-2009.5, 2009.5-2014.4, and 2014.4-2018.5. The cycle length is 3 years, 3 years, 5 years, and 4 years, respectively, with an average cycle length of 3.75 years, which conforms to the traditional pig cycle.

Research on the pig cycle in the United States also usually relies on the price ratio of pigs-to-corn (Holt and Craig [43]). China's pig cycle and the pig-to-corn ratio cycle also show considerable consistency (Zhou and Koemle [44]), as shown in Figure 2.

Other factors may also affect pig prices, such as new technologies, economic cycles, inflation, and import and export of pork. In the initial model, we will not consider these factors for the time being.

Based on the above analysis, the price function of live pigs is constructed as follows:

Pig price $=$ trader's expected price $*$ effect of stock supply ratio on price $*$ effect of cost on price

Among them,

The dealer's expected price $=$ INTEGRAL (the dealer's expected price change, pig price)

Trader's expected price change $=($ indicator price - trader's expected price)/trader's time to adjust expected price

Indicator price $=$ MAX (pig price, lowest price)

Lowest price $=$ expected variable cost of breeding

The expected variable cost of breeding is characterized by the grain ratio of profit and loss of pigs. According to the 


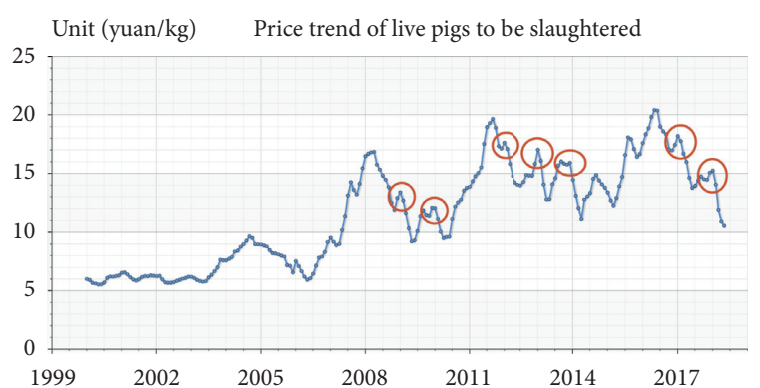

Figure 1: Price trend of live pigs to be slaughtered in China. The dates of the red circles are December 2008-January 2009; December 2009-January 2010; December 2011-January 2012; December 2012January 2013; December 2013 -January 2014; December 2016January 2017; December 2017-January 2018. The Spring Festival effect of pork consumption is obvious when the pig price falls. The data are from the China Animal Husbandry Information Network.

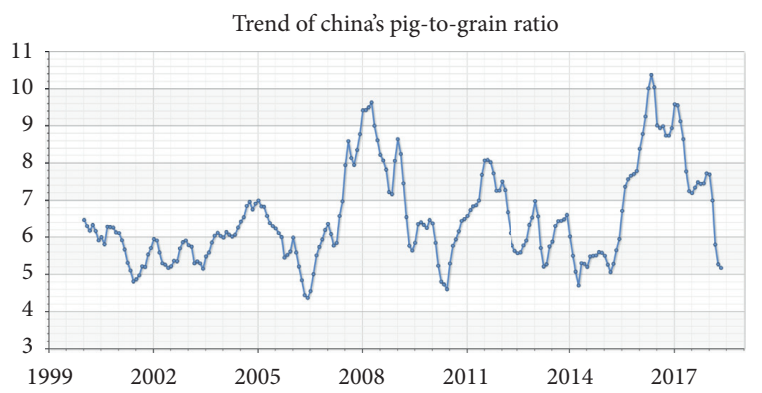

FIgure 2: Trend of China's pig-to-grain ratio. The data are from the China Animal Husbandry Information Network.

China Animal Husbandry and Veterinary Yearbook, China's profit-loss pig-to-grain ratio is 5.5. The price of corn is shown in Figure 3.

Assuming the price of corn is 2 yuan $/ \mathrm{kg}$, the expected variable pig breeding cost is 11 yuan $/ \mathrm{kg}$.

Impact of stock supply ratio on price $=$ POWER (relative stock supply ratio, elasticity of price to stock supply ratio)

Relative stock supply ratio= perceived stock supply ratio/reference stock supply ratio

The reference stock supply ratio refers to the average ratio of pork to consumption in the market. Reference inventory includes the sum of pork inventory held by slaughterhouses, distributors, wholesalers, retailers, and consumers. According to industry experience, it is estimated to be 1.5 months.

Perceived inventory supply ratio $=\mathrm{SMOOTH}$ (inventory supply ratio, inventory perceived time)

Stock supply ratio = supply-side pork stock/pork supply rate

Cost-to-price impact $=1+$ price-to-cost elasticity $*$ (expected breeding cost/trader's expected price -1 )

The price-to-cost elasticity reflects the influence of cost to the price. When price-to-cost elasticity is close to 1 , it indicates that cost has a greater impact on price, such as

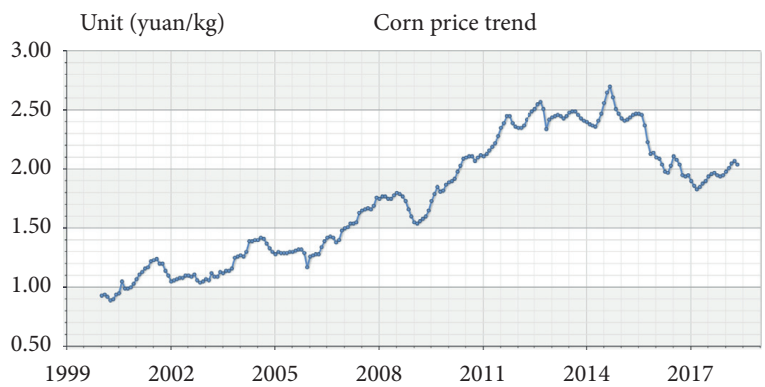

Figure 3: China 2000-2017 corn price trend chart. The data are from the China Animal Husbandry Information Network.

some agricultural products; when price-to-cost elasticity is close to zero, it indicates that cost has little effect on the price, such as some luxury goods.

The price construction method has universal significance and is supported by many research results. The adaptive expected price model has shown good prediction ability (Nerlove [20]; Gerlow et al. [22]). Econometric studies also showed that prices will respond to the inventory supply ratio and unit cost (Sterman [5]).

3.2. Pork Demand Influencing Factors' Analysis. Similarly, the pork demand function is set based on the anchor and adjustment process. The pork demand function is constructed as follows:

$$
D=D^{*} \times f_{1}\left(\operatorname{signal}_{1}\right) \times f_{2}\left(\operatorname{signal}_{2}\right), \ldots, f_{n}\left(\operatorname{signal}_{n}\right) .
$$

Among them, the anchor value $D^{*}$ is assumed to be the average pork consumption from 2010 to 2017. Studies have shown that factors affecting pork demand include income, price, consumption preferences, population size, per capita pork consumption, substitutes, seasonal changes, pig epidemics, and holidays.

In recent years, the growth rate of China's pork consumption has begun to decline. From 2001 to 2005, the average annual growth rate of total pork consumption was $3.37 \%$, from 2005 to 2010, it fell to $2.37 \%$, and from 2010 to 2017, it further fell to $1.03 \%$. Economic principles show that an increase in residents' income will lead to an increase in pork consumption. According to the China Animal Husbandry and Veterinary Yearbook, China's per capita pork consumption reached a maximum of $41.5 \mathrm{~kg}$ in 2014. The income of Chinese residents increased, but pork consumption decreased from 2015 to 2017, indicating that the increase in income of residents has no effective impact on pork consumption at this stage. The decrease of pork consumption in China in recent years is also related to the diversified consumer preferences of the meat diet.

The trend of pork consumption and pig slaughter in China is the same and showed obvious seasonal fluctuation: November to January of the following year is the peak period of consumption in the whole year, while March to May after Spring Festival is the weakest period. Generally speaking, pork consumption started to pick up from August until Spring Festival. After Spring Festival, the sales volume 
dropped rapidly, and then the consumption entered a downturn period until August when it returned to positive growth. Statistics on pig prices in China from 2010 to 2018 are shown in Table 1.

Considering the principle of matching supply and demand, this paper depicts the fluctuation of demand through slaughter quantity data of slaughter enterprises, as shown in Table 2.

The pig demand function is constructed as follows:

Indicating pork demand rate = population quantity $*$ per capita consumption $*$ influence of seasonal fluctuation on consumption $*$ influence of price on consumption

Given the irregularity of seasonal fluctuation and the incompleteness of data, this paper makes a simplified treatment and constructs a table function of seasonal fluctuation on consumption based on Table 2, as shown in Figure 4.

Impact of price on consumption $=1+$ impact coefficient of price on consumption $*$ (breeding cost - pig price)/pig price

The influence coefficient of price on consumption is calculated by the price corresponding to the annual output. The statistical results are shown in Table 3 .

From Table 3, it can be seen that pig prices have an impact on consumption. The prices in 2012, 2013, 2015, and 2017 are close, with an average price of 15.215 yuan $/ \mathrm{kg}$ and a relative change in average consumption of 1.0071 . When the price of live pigs was lower in 2014, the consumption was higher. When pig prices were higher in 2016, consumption was lower. Consumers will form historical prices to judge whether the current prices are high or low and adjust consumption accordingly, which economists call "reference price effect." According to the data in the table, the influence coefficient of the pig price on consumption is calculated to be 0.25 .

Pork demand is adjusted with delay around demand indicated by commodity prices, so consumption will not have an immediate response to prices. According to this, the pig demand function is constructed as follows:

Pork demand rate $=$ SMOOTH (indicating pork demand rate, demand adjustment time)

3.3. Pork Supply Influencing Factors' Analysis. For industrial products, the key to the demand cycle is the core variable that determines the price. For agricultural products, the supply cycle is the core variable that determines the price. This is because the production of industrial products is relatively stable and can be planned and increased or decreased at any time. Agricultural products, on the contrary, are rigid in demand and relatively stable in consumption, but highly uncertain in supply. They are the main sources of price fluctuations. Besides, the supply cycle of agricultural products is long while the production cannot be resumed as planned. Therefore, it is difficult to resume production in a short period in case of insufficient supply.
According to the principles of behavioral economics, decision makers often make predictions based on convincing evidence to make decisions. The expected pig price function is constructed according to the extrapolated expectation.

Expected price $=$ perceived price $*$ impact of trend on expected price

Perceived price $=\mathrm{SMOOTH}$ (pig price, the time required to perceive current pig price)

Impact of trend on expected price $=$ EXP (expected growth rate ratio $*$ expected price time span)

Meadows [45] measured that the expected price adjustment time was about 6 months and then constructed the expected growth rate proportional function as follows:

Expected growth rate ratio $=$ TREND (pig price, 6,0 )

According to the expected price, the expected profit rate function is constructed as follows:

Expected profit rate $=($ expected price - average breeding cost)/average breeding cost

Philip Green Wright said: "Business and price cycles are cyclical recurrences caused by large-scale psychology through capitalist production." Economic research showed that when profits increase, existing enterprises tend to expand their scale as soon as possible, and new enterprises will enter the market. When losses occur, existing enterprises tend to reduce production scale, and enterprises with poor profits will withdraw from the market.

According to the anchor adjustment rule as well as the expected profit rate, the expected sow number function is constructed as follows:

Expected sows $=$ number of industry reference sows $*$ effect of expected profit rate on expected sows Effect of expected profit rate on expected sow number $=$ IF THEN ELSE (expected profit rate $>0,1+$ profit impact coefficient $*$ expected profit rate, $1+$ loss impact coefficient $*$ expected profit rate)

Based on the average price of live pigs and the number of live pigs sold in China from 2010 to 2017, this paper determines the profit impact coefficient and loss impact coefficient (Table 3) and then calculates the profit impact coefficient to be 0.2 and the loss impact coefficient to be 0.13 .

The breeder adjusts the number of sows in stock according to the expected number of sows, thereby constructing a sow increase rate function as follows:

Sow increase rate $=$ DELAY1 $($ MAX (sow stock adjustment rate + sow elimination rate, 0 ), 1)

Sow stock adjustment rate $=($ expected sow number-number of sows able to reproduce)/sow stock adjustment time

Meadows [45] measured that the adjustment time of sow stock was about 5 months. When the market is prosperous, the breeder will prolong the breeding time of the sow, even if the number of farrowing of the sow is lower than the average 
TABLe 1: Statistics of pig prices in China from 2010 to 2018.

\begin{tabular}{lcccccccccc}
\hline Month/year & 2010 & 2011 & 2012 & 2013 & 2014 & 2015 & 2016 & 2017 & 2018 & Average \\
\hline Jan. & 12.05 & $\mathbf{1 3 . 8 8}$ & 17.65 & 17.04 & 14.46 & 13.38 & 17.62 & 18.22 & 15.25 & 15.51 \\
Feb. & 11.14 & 14.35 & 17.10 & 16.09 & 13.11 & 12.71 & 18.37 & 17.78 & 14.06 & 14.97 \\
Mar. & 10.06 & 14.78 & 15.83 & 14.07 & 12.05 & $\mathbf{1 2 . 2 7}$ & 18.90 & 16.71 & 11.91 & 14.06 \\
Apr. & $\mathbf{9 . 5 3}$ & 15.05 & 14.80 & $\mathbf{1 2 . 8 0}$ & $\mathbf{1 1 . 1 2}$ & 12.91 & 19.84 & 16.00 & 10.93 & $\mathbf{1 3 . 6 6}$ \\
May & 9.62 & 15.53 & 14.25 & 12.82 & 12.79 & 13.92 & 20.45 & 14.63 & $\mathbf{1 0 . 5 7}$ & 13.84 \\
Jun. & 9.64 & 17.54 & 14.05 & 14.10 & 13.06 & 14.72 & 20.41 & $\mathbf{1 3 . 7 8}$ & 11.32 & 14.29 \\
Jul. & 11.14 & 18.98 & $\mathbf{1 4 . 0 0}$ & 14.61 & 13.34 & 16.59 & 19.03 & 13.96 & 12.02 & 14.85 \\
Aug. & 12.19 & 19.33 & 14.28 & 15.70 & 14.56 & 18.12 & 18.62 & 14.41 & 13.36 & 15.62 \\
Sept. & 12.55 & 19.68 & 14.89 & 16.04 & 14.88 & 17.94 & 18.36 & 14.75 & 14.14 & 15.91 \\
Oct. & 12.78 & 18.93 & 14.85 & 15.86 & 14.42 & 17.10 & 17.06 & 14.52 & 14.10 & 15.51 \\
Nov. & 13.55 & 17.35 & 14.83 & 15.77 & 14.09 & 16.43 & $\mathbf{1 6 . 9 8}$ & 14.47 & 13.87 & 15.26 \\
Dec. & $\mathbf{1 3 . 7 9}$ & 17.15 & 15.83 & 15.92 & 13.81 & 16.68 & 17.46 & 15.07 & 13.95 & 15.52 \\
Average & 11.50 & 16.88 & 15.20 & 15.07 & 13.47 & 15.23 & 18.59 & 15.36 & 12.96 & 14.92 \\
\hline
\end{tabular}

The data are from China's Animal Husbandry Information Network. The italic font in the table is the highest price for the current year, the bold font is the lowest price for the current year, and 14.92 yuan $/ \mathrm{kg}$ in the lower right corner is the average pig price from 2010 to 2018 .

TABLE 2: Slaughter quantity of pig slaughtering enterprises above the national scale.

\begin{tabular}{lccccccccccccc}
\hline Month & Jan. & Feb. & Mar. & Apr. & May & Jun. & Jul. & Aug. & Sept. & Oct. & Nov. & Dec. & Average \\
\hline Slaughter quantity & 2198 & 1809 & 1658 & 1735 & 1695 & 1589 & 1491 & 1500 & 1703 & 1817 & 1891 & 2293 & 1782 \\
Relative rate of change & 1.23 & 1.02 & 0.93 & 0.97 & 0.95 & 0.89 & 0.84 & 0.84 & 0.96 & 1.02 & 1.06 & 1.29 & 1 \\
\hline
\end{tabular}

The relative change rate is the slaughter quantity of the current month divided by the average value. The data are from the China Animal Husbandry and Veterinary Yearbook.

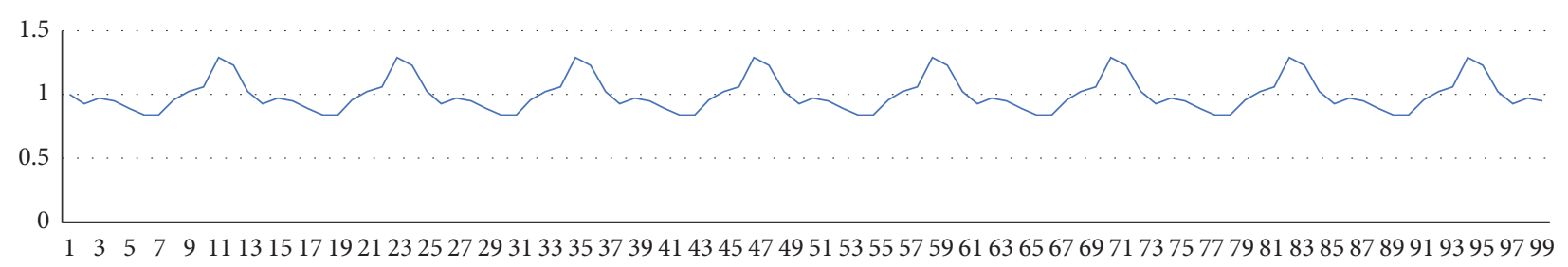

FIGURE 4: Influence of seasonal fluctuation on pig consumption. The data are calculated by the author.

TABle 3: Statistics of China's live pig output, consumption, and annual average price from 2010 to 2017.

\begin{tabular}{|c|c|c|c|c|c|c|}
\hline Year & $\begin{array}{l}\text { Output (unit: } \\
10,000 \text { pigs) }\end{array}$ & $\begin{array}{l}\text { Population (unit: } \\
10,000 \text { people) }\end{array}$ & $\begin{array}{c}\text { Annual per capita } \\
\text { consumption (unit: head/ } \\
\text { person/year) }\end{array}$ & $\begin{array}{l}\text { Relative changes in } \\
\text { per capita } \\
\text { consumption }\end{array}$ & $\begin{array}{l}\text { Average price } \\
\text { (unit: yuan/ } \\
\text { kg) }\end{array}$ & $\begin{array}{c}\text { Per capita consumption } \\
\text { (unit: head/ } \\
\text { person/year) }\end{array}$ \\
\hline 2017 & 68,800 & 139,008 & 0.4949 & 0.9726 & 15.36 & \multirow{8}{*}{0.5089} \\
\hline 2016 & 68,500 & 138,300 & 0.4953 & 0.9733 & 18.59 & \\
\hline 2015 & 70,825 & 137,500 & 0.5151 & 1.0122 & 15.23 & \\
\hline 2014 & 73,500 & 136,800 & 0.5373 & 1.0558 & 13.47 & \\
\hline 2013 & 71,557 & 136,100 & 0.5258 & 1.0332 & 15.07 & \\
\hline 2012 & 69,628 & 135,400 & 0.5142 & 1.0105 & 15.2 & \\
\hline 2011 & 66,170 & 134,700 & 0.4912 & 0.9653 & 16.88 & \\
\hline 2010 & 66,686 & 134,100 & 0.4973 & 0.9772 & 11.5 & \\
\hline
\end{tabular}

The output data are from China's Animal Husbandry and Veterinary Yearbook, and population data are from the China statistical yearbook. Other data are calculated by the author.

level. When the industry suffers serious losses, many farmers slaughter sows to speed up the elimination of sows. For example, the slaughter of sows occurred in 1999 and 2006. Judging from experience, the number of slaughtered sows should be in the range of $1 \%-5 \%$. According to this, the elimination adjustment time function is constructed as follows:
Elimination adjustment time $=$ elimination adjustment coefficient $*$ expected profit margin

Due to the lack of sufficient data, simplified processing is done here. After calculation, the elimination adjustment coefficient is equal to 1 . 
Sow elimination rate $=$ number of sows capable of reproduction/(average cycle of sow reproduction + elimination adjustment time)

The process of pig fattening can be divided into pregnancy delay and fattening delay. Among them, $90 \%$ of piglets were born 111 to 119 days after conception, which is a highorder delay (Meadows [45]). The difference in fattening delay is larger than pregnancy delay, which can be expressed by third-order delay. According to the China Animal Husbandry and Veterinary Yearbook, the fattening time of live pigs is about 170 days, and the number of sows giving birth is 2.2 times a year. The average number of piglets per litter provided by sows is also increasing. In 2015, the average number of piglets per litter is 7.48. In 2017, it reached about 9. According to this, the formula is constructed as follows:

Pregnancy rate $=$ number of sows capable of reproduction $*$ monthly pregnancy frequency $*$ average number of piglets per litter

Birth rate $=$ DELAY FIXED (pregnancy rate, pregnancy cycle)

Supply rate $=$ DELAY3 (birth rate, average fattening time)

Because pig diseases are quite unpredictable, this paper does not consider the impact of diseases on the pig supply chain. Most pig diseases have not significantly affected the stability of the pig supply chain.

\section{Model Construction and Initialization}

According to the above analysis, the system dynamics model of the pig industry is built by using system dynamics software Vensim PLE, as shown in Figure 5.

According to price theory, there is general equilibrium. Schumpeter [46] thought that, as the pig market is close to a completely competitive market, new enterprises will enter the market as long as there is profit, and then the final equilibrium is zero profit price. However, our common sense is that profits exist. Schumpeter explained that entrepreneurs have produced value surplus in the recombination of production factors. The surplus will gradually disappear as production continues. Profit is a special case of value surplus. That is, under the condition of balance between supply and demand, the system will move to the equilibrium gradually, making "Pig price" = "Dealer expected price" = "Expected breeding cost." The time required to achieve equilibrium depends in part on the speed with which farms learn from experience. According to "Little's rule" (Stock $=$ Rate $*$ Time), the initial sow pregnancy preparation delay is $1,119,911$, the sow population is $35,727,335$, the pregnancy delay is $24,894,004$, the fattening delay is $327,762,575$, the pork stock on the supply side is $88,425,155$, and the monthly pork demand is $58,950,103$. Other parameters are shown in Table 4.

The simulation time is 100 months, and the simulation step length is 1 month. The simulation results are shown in Figure 6.
The simulation reveals two characteristics of the pig supply chain:

(1) Oscillation: the price of live pigs oscillates around the breeding cost. The price of live pigs reached the highest value in the 8th, 53rd, and 99th months, $20.49,20.76$, and 19.70 yuan $/ \mathrm{kg}$, respectively. The average pig price for 100 months is 14.61 yuan $/ \mathrm{kg}$, with a variance of 10.26 . The highest price is 20.76 yuan $/ \mathrm{kg}$, the lowest price is 9.98 yuan $/ \mathrm{kg}$, and the price difference is 10.78 yuan $/ \mathrm{kg}$. The pig cycle is 45 months and 46 months, respectively, with an average pig cycle of 3.79 years, which is very close to the average pig cycle of 3.75 years in China since 2003.

(2) Phase lag: there is a significant phase lag relationship between pig price, number of sows capable of reproduction, and supply rate, i.e., its peak and trough appear in turn, and there is a lag delay.

Oscillation and phase lag are common phenomena in the supply chain (Sterman [47]). Note that the pig price is not a simple mirror image of the pig supply rate.

\section{Numerical Experiments and Analysis}

The purpose of this section is to measure the degree of mitigation of different supply chain management strategies on the pig cycle, especially on the degree of fluctuation in the pig price. This section verifies the effectiveness of the supply chain management strategy from the perspective of enterprises (reducing the pig breeding cost and countercyclical regulation) and from the perspective of government (government macroregulation).

5.1. Reducing the Pig Breeding Cost. The pig breeding cost greatly affects the pig price. Assuming that the cost of pig breeding in China is reduced to $2 / 3$ and $1 / 2$ of the original cost, i.e., 9.81 yuan $/ \mathrm{kg}$ and 7.36 yuan $/ \mathrm{kg}$, the other parameters remain unchanged. The simulation results of pig prices are shown in Figure 7.

By reducing the pig breeding cost, the fluctuation of pig price had greatly stabilized.

When pig breeding cost $=9.81 \mathrm{yuan} / \mathrm{kg}$, the average price of live pigs dropped to 9.71 yuan $/ \mathrm{kg}$. The difference between the highest price of 12.72 yuan $/ \mathrm{kg}$ and the lowest price of 7.52 yuan $/ \mathrm{kg}$ is 5.2 yuan $/ \mathrm{kg}$. The price fluctuation of live pigs decreased by $51.76 \%$. When pig breeding cost$=7.36$ yuan $/ \mathrm{kg}$, its 100 -month variance of pig price is only 0.53 . The average price of live pigs dropped to 7 yuan $/ \mathrm{kg}$. The difference between the highest price of 8.75 yuan $/ \mathrm{kg}$ and the lowest price of 5.67 yuan $/ \mathrm{kg}$ is 3.08 yuan $/ \mathrm{kg}$. The price fluctuation of live pigs decreased by $71.37 \%$. The simulation shows that the reduction of pig breeding costs can bring stability to the pig market.

The price of live pigs in Europe and the United States is more stable. The reasons may include the following: lower pig breeding cost; the pig market opens longer, and pig farmers have more experience in the pig cycle; and Europe 


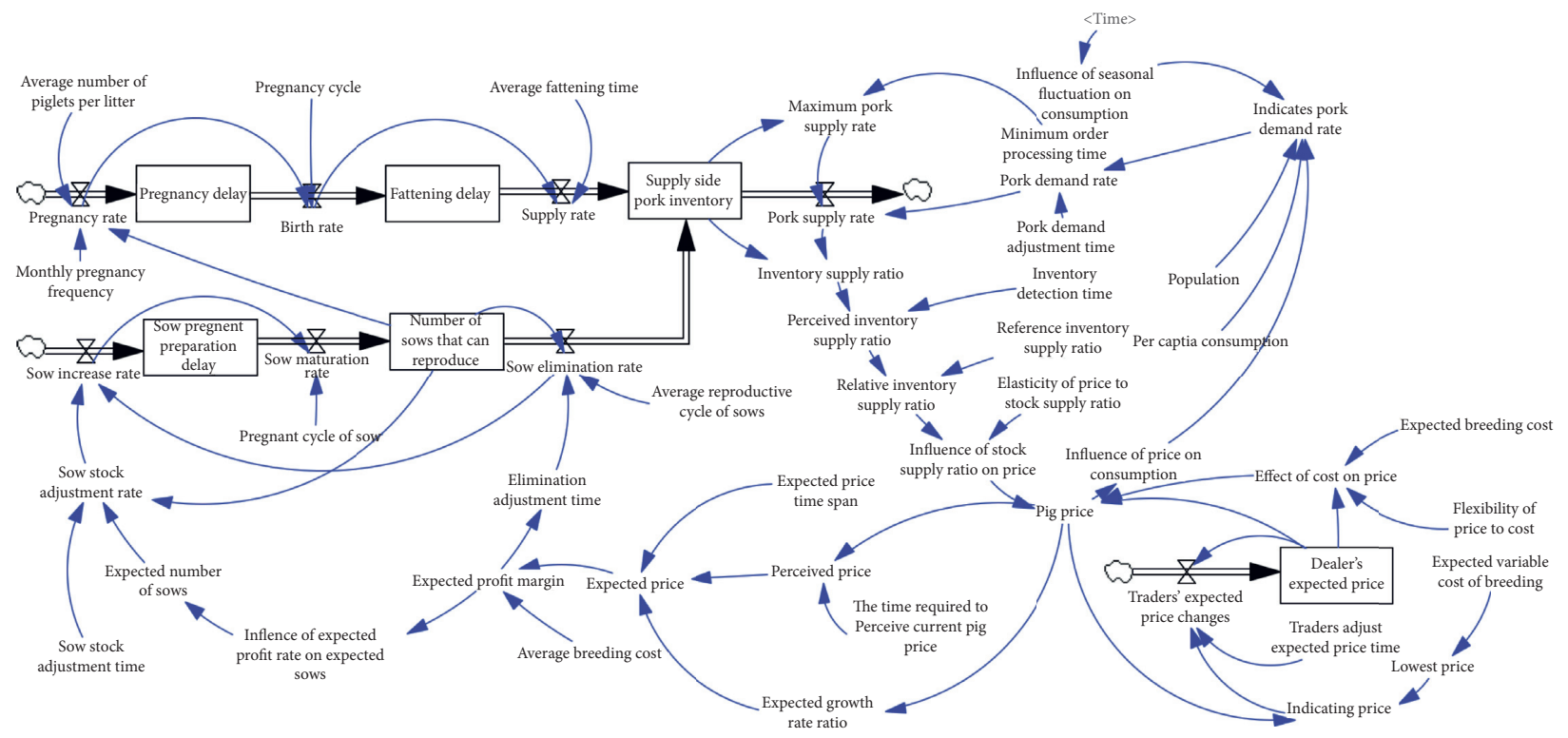

FIGURE 5: Pig supply chain stock flowchart.

TABLE 4: Some parameters of pig industry models.

\begin{tabular}{lcc}
\hline Parameter & Number & Unit \\
\hline $\begin{array}{l}\text { Time for sows to prepare for } \\
\text { pregnancy }\end{array}$ & 1 & Month \\
Average reproductive cycle of & 30 & Month \\
sows & & \\
The average number of piglets per & 9 & Head/nest \\
litter & & Nest/head/month \\
Monthly pregnancy frequency & 0.1833 & Month \\
Pregnancy cycle & 3.8 & Month \\
Average fattening time & 5.56 & Month \\
Sow stock adjustment time & 5 & Month \\
Reference inventory supply ratio & 1.5 & Month \\
Minimum order processing time & 1 & Month \\
Expected price period & 3 & Month \\
Adjustment time of pork demand & 6 & Dimensionless \\
Elasticity of price to stock supply & -0.75 & Month \\
ratio & 0.5 & Dimensionless \\
Inventory detection time & 0.5 & Month \\
Flexibility of price to cost & 12 & Ten thousand \\
Traders adjust expected price time & people \\
Population & 139,008 & Head/ \\
Per capita consumption & 0.0424 & person/month \\
Expected breeding cost & 14.72 & yuan/kg \\
\hline Popult
\end{tabular}

Population data are from the China Statistical Yearbook. Other parameters are calculated by the author.

and the United States have a higher degree of scale and more stable production. Figure 8 shows the comparison of live pig prices between China, the United States, and Europe from 2000 to 2013.

With the reduction of pig breeding costs, the price curve that eliminates periodic fluctuations will tilt downward, resulting in a decrease in pig market profits. The ideal equilibrium state in the economic system had never reached, but it is constantly "pursued." The competition between enterprises broke the balance of the economic system, making the economic system struggle around the new equilibrium position (new pig breeding cost).

5.2. Countercyclical Adjustment. The countercyclical strategy refers to the fact that producers increase production when the overall production capacity is low, thereby limiting the high prices caused by short-term supply shortages. In the case of high overall production capacity, production is reduced to minimize losses. T. S. Adams also pointed out that "predict the cycle is to make the cycle invalid." If the prediction accuracy is improved, the pig cycle can be suppressed or even eliminated. However, the unpredictability of the cycle (i.e., imperfect information) will continue because the current prediction model cannot fully calculate all the dynamics of the price cycle time path. A common mistake made by forecasters is to treat seemingly random disturbances as white noise. Disturbances may be part of the nonlinear dynamics of the system.

However, the long-standing business cycle shows that the regularity of the business cycle is very strong and cannot be changed through countercyclical adjustment and speculative strategies. The profit of countercyclical adjustment must exceed the cost of adjustment; the high adjustment cost made the profit of countercyclical production decline in the past century. The behavior of "sticky" producers explains the persistence of the cycle. Increasing anticipation of the cycle may weaken the normal periodic movement, but it cannot prevent the cycle from happening.

Assuming that the countercyclical adjustment is well implemented, the profit impact coefficient is reduced to 0.15 , and the loss impact coefficient is reduced to 0.1, the simulation results are shown in Figure 9(a). When the profit impact coefficient is reduced to 0.12 and the loss impact coefficient is reduced to 0.8 , the simulation results are shown 


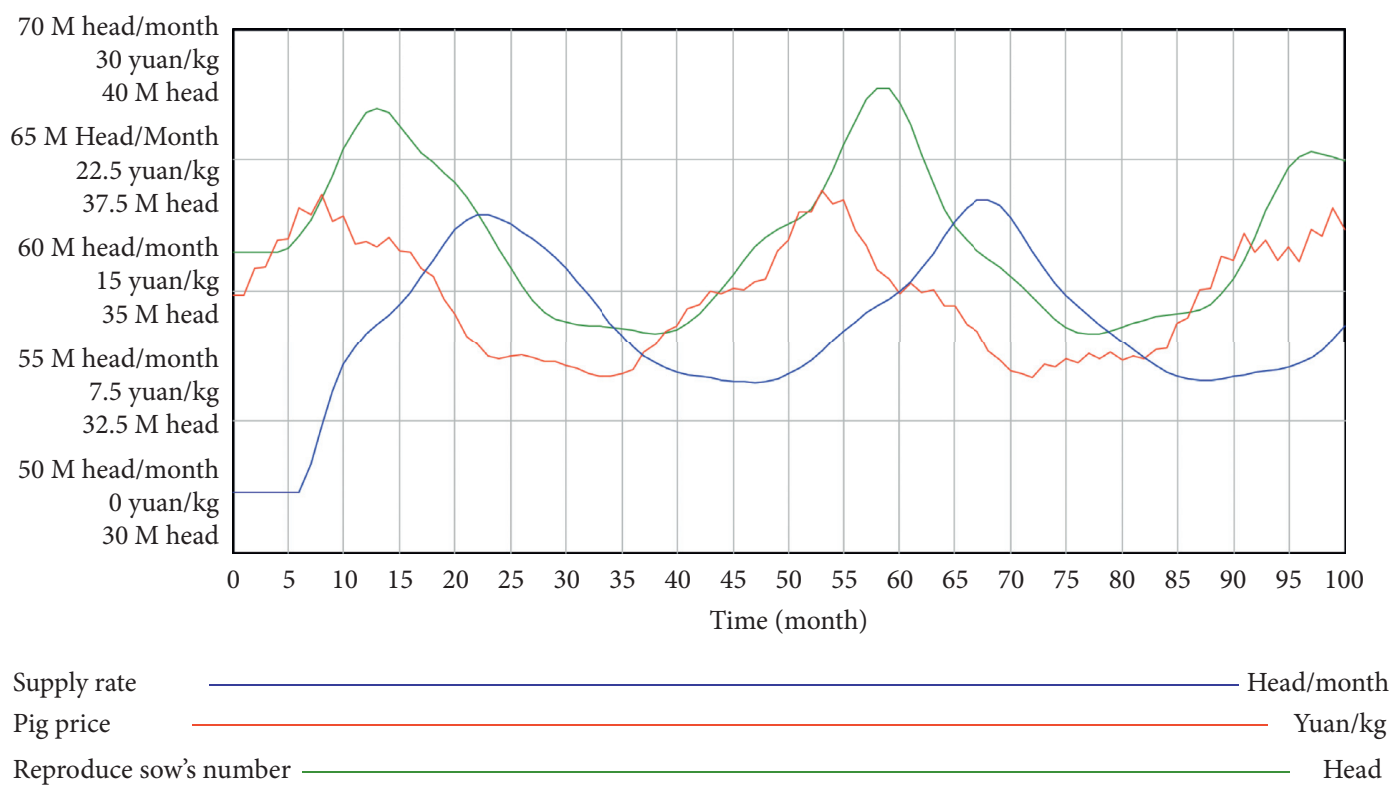

FIGURE 6: Simulation results of the pig supply chain.

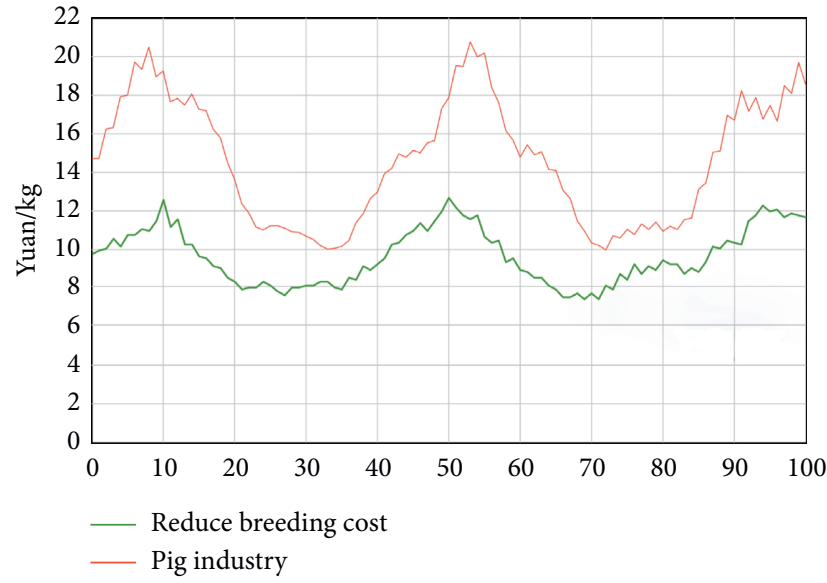

(a)

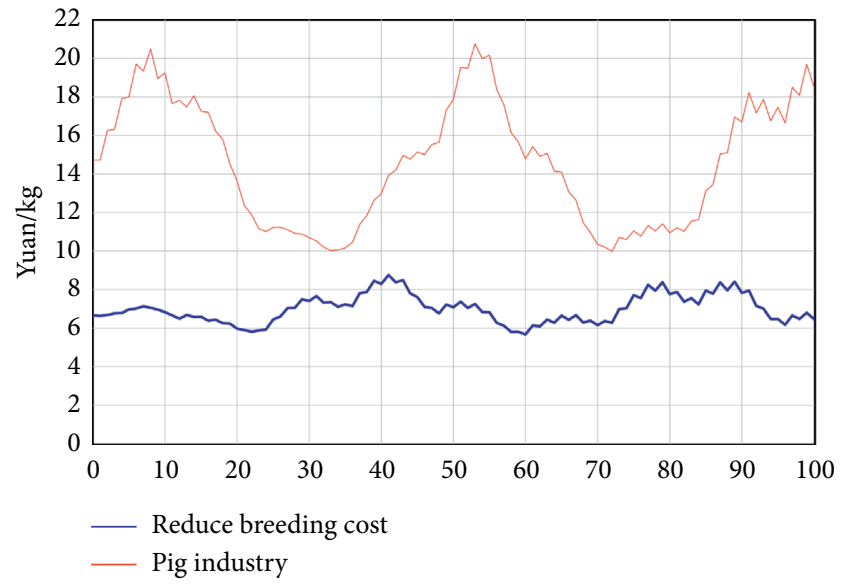

(b)

Figure 7: Effect of reducing pig breeding cost on the pig price. (a) Pig breeding cost $=9.81$ yuan $/ \mathrm{kg}$. (b) Pig breeding cost $=7.36$ yuan $/ \mathrm{kg}$.

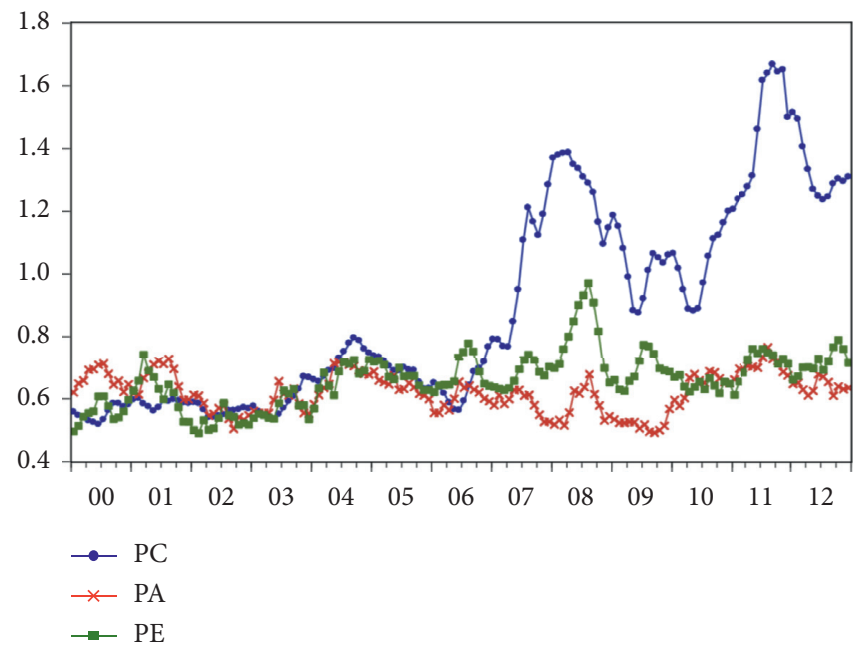

Figure 8: Comparison of Chinese pig price, American pig price, and European pig price. The abscissa is the year, and the ordinate is the pig price (unit: USD $/ \mathrm{kg}$ ). The picture is taken from Hog Price Transmission in Global Markets: China, EU, and U.S., 2014. 


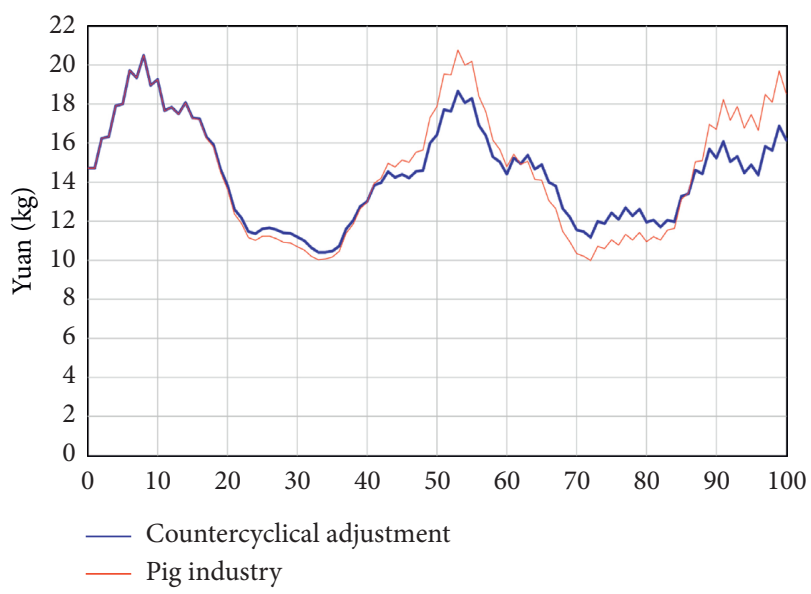

(a)

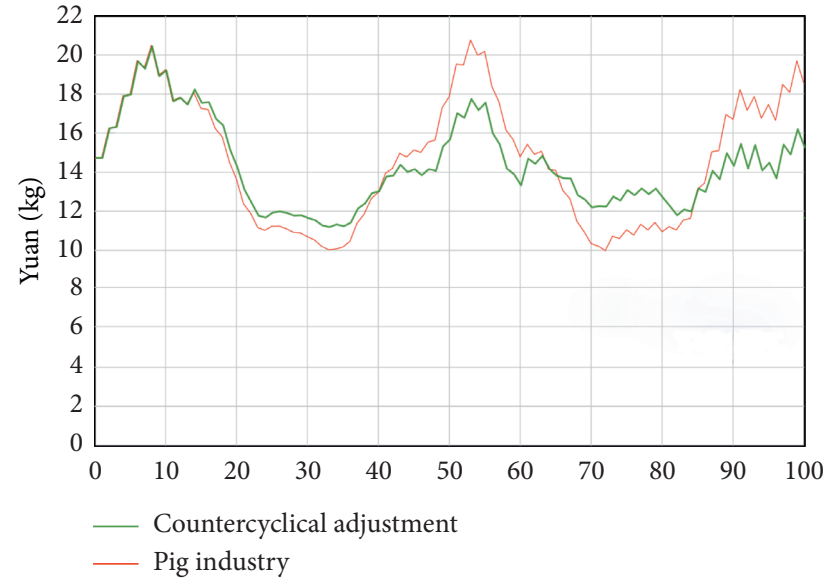

(b)

Figure 9: Effect of countercyclical adjustment on the pig price.

in Figure 9(b). Pay attention to the lag of countercyclical adjustment.

\subsection{Government's Macrocontrol Strategy. Frank Knight} pointed out that we should be alert to the free market because the free market creates wealth by stimulating human greed and other dark sides. There are many evil sides in the market economy. Based on this, the government should play its macrocontrol role to ease the fluctuation of pig prices.

The government's macrocontrol measures for the pig market include the meat reserve policy and import and export policies, as well as financial subsidy policy.

Import and export policies are also conducive to the stability of the pig market. For example, Britain is no longer self-sufficient in pork: pork imports have grown steadily over the past 20 years and now exceed domestic production. As a result, the UK pork prices have become more stable since 2000. Meanwhile, pork imports have problems such as food safety, then the government has adopted strict control policies on pig imports, so China's pig supply chain is a "selfsufficient" model. Imports of pork averaged 940,000 tons from 2013 to 2017, with about 11.575 million pigs, accounting for $1.64 \%$ of the annual consumption. When the price of live pigs is high, the government will increase imports.

Financial subsidies can also effectively guarantee the supply of a live pig market. When losses occur, financial subsidies prevent farmers from significantly reducing the scale of farming and can promote the restoration of farming. When the price of live pigs rose and then the market was optimistic, many enterprises often expanded their scale or entered pig farming across industries, increasing the supply of live pigs and then bringing down the price of live pigs again. So, when the price of pigs fell, the government needed corresponding subsidies for farmers to operate stably.
According to this, the government regulation function is constructed as follows:

Government regulation = IF THEN ELSE (government-perceived price $>$ pig breeding cost, import and delivery coefficient $*$ government-perceived price, export and storage coefficient $*$ (government-perceived price - pig breeding cost)/government-perceived price) Government-perceived price $=$ SMOOTH (pig price, government-perceived price time)

Pork imports $=$ import and release coefficient $*$ government-perceived price

To simplify processing, the delay in importing pork was ignored. The government perceives the price set at one month. As the government implements financial subsidies, it is assumed that the loss reduction impact coefficient is 0.12 . Since the initial model did not consider the macrocontrol of the government, the import and delivery coefficient was set at 10,000, and the export and storage coefficient was set at 50,000; the stock flowchart is shown in Figure 10, and the simulation result is shown in Figure 11.

Under the macrocontrol of the government, the pig market is more stable. The average price of live pigs was 14.39 yuan $/ \mathrm{kg}$, and the variance was reduced to 7.07 . The difference between the highest price of 19.94 yuan $/ \mathrm{kg}$ and the lowest price of 10.32 yuan $/ \mathrm{kg}$ was 9.62 yuan $/ \mathrm{kg}$, lower than the previous difference of 10.78 yuan $/ \mathrm{kg}$.

Despite the high cost of the meat reserve policy and no significant effect on market stability, it has two major roles. First, during the period of high prices, panic will spread, and people will be exhausted. The government should not only avoid the loss of high prices to the public but also try to protect the public from the impact of panic. The policy of reserve meat is a "heart-strengthening needle" to restore market stability during the period of low pig prices and a "sedative" to cool the overheated 


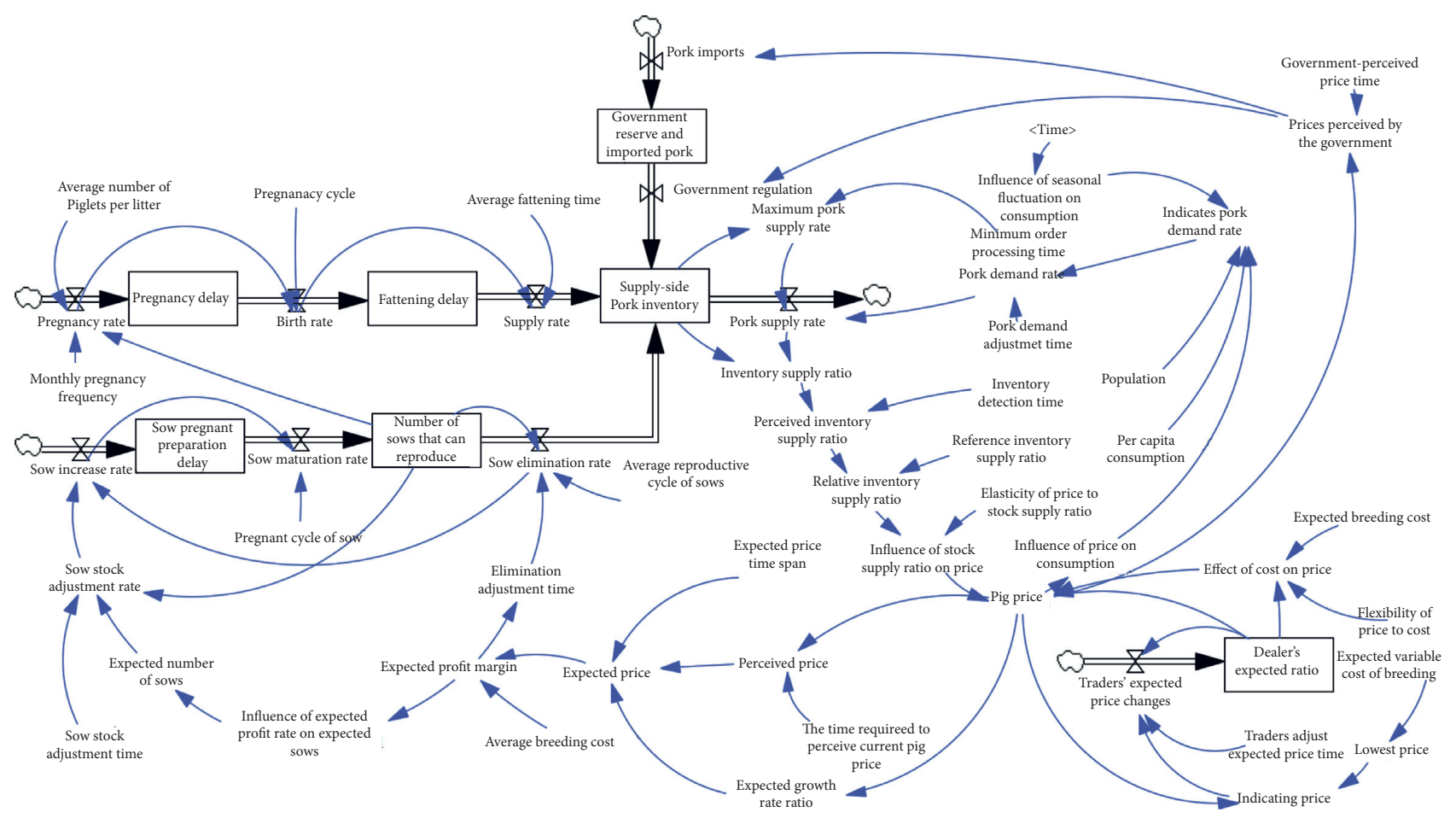

FIGURE 10: The stock flowchart of China's pig supply chain regulated by the government.

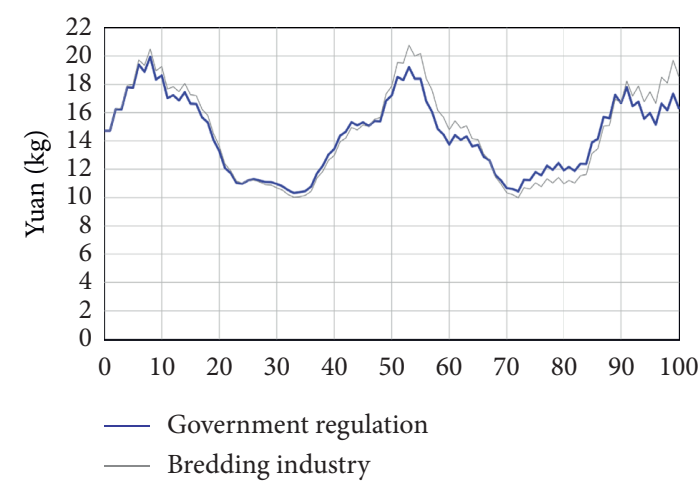

(a)

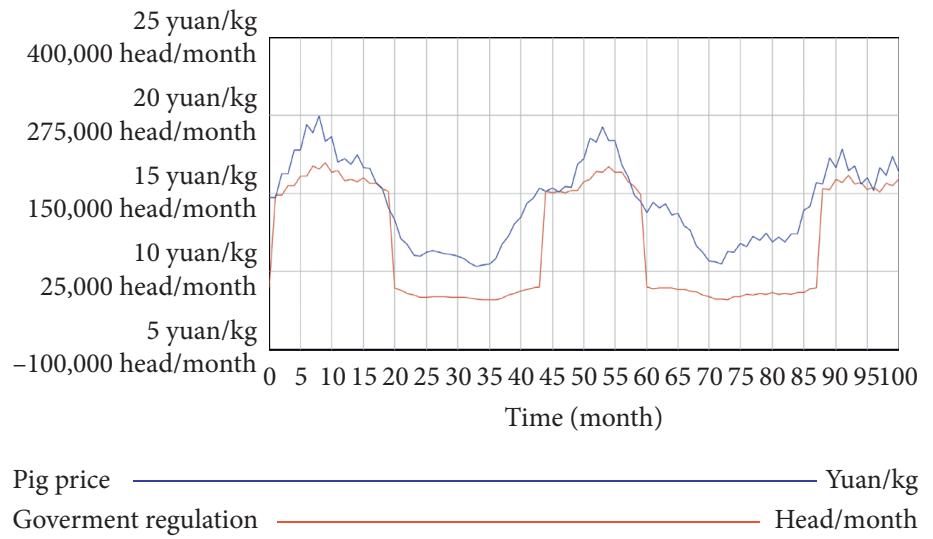

(b)

FIGURE 11: (a) Stabilizing effect of the government regulation on the pig market; (b) the relationship between the pig price and the number of pigs imported and released by the government.

market during the period of high pig prices. Second, when the government buys at a low price, it can increase its fiscal revenue by putting in at a high price. At the same time, we should also realize that this policy has encroached on a certain market share and compressed the profit space of the pig supply chain.

Import and export policies are convenient and flexible, but it should be noted that early regulation is better than late regulation. In particular, when the price of live pigs is depressed due to the increase in the supply of live pigs, the government should ensure an increase in pork exports. Besides, when there is overcapacity, the government should actively seek ways to expand exports. China's difficulties in increasing pork exports lie in the following: first, the high pig breeding cost leads to the lack of price competitiveness; second, China accounts for half of the world's pig consumption, and the international market is relatively limited; and third is food safety.

Financial subsidy policy is an effective policy to stabilize the market, but more subsidies should be given to small farmers; this also reflects the fairness concern and the fairness of income distribution. Besides, subsidies are only needed to help enterprises solve infrastructure or negative externalities. Therefore, the government should stop subsidizing large enterprises to avoid the deterioration of income distribution and the spread of corruption. 
Note that the market will also generate compensatory feedback to the direct regulation of the government, and then the compensatory feedback will weaken the direct regulation effect of the government. Industrial policies will also mislead entrepreneurs and make them invest resources in areas or projects that they should not invest, thus causing overcapacity and harming the healthy development of the industry. While the government intervenes, it creates rent and causes rent-seeking behavior, which in turn leads to corruption and unfair income distribution.

The existence of a large number of small-scale farmers may be one of the important reasons for the price fluctuation of pork in China to be larger than Europe and America. The "company + farmer" model can effectively stabilize the scale of small- and medium-sized farmers, which may be the development direction of small- and medium-sized farmers in the future.

\section{Conclusion}

The "pig cycle" originates from the interaction between the physical delay in pig breeding and the capacity of decisions made by individual producers/investors under the guidance of bounded rationality; in addition, pig cycle is interfered by pig diseases, industrial policies, natural environment, etc.. The "pig cycle" takes the pig endogenous cycle as the expected value and fluctuates up and down around the expected value.

This paper constructs a system dynamics model of China's pig supply chain and then simulates the strategy of stabilizing the pig market. Simulation results show that reducing the pig breeding cost and countercyclical adjustment, as well as government macrocontrol, can effectively stabilize the pig market. Among them, reducing the pig breeding cost is a long-term strategy to stabilize the pig market. The government's direct regulation occupies a large number of resources that causes compensation feedback. Therefore, the government should weaken the direct intervention strategy, starting with reducing the pig breeding cost and countercyclical adjustment, and play the regulatory role of "invisible hand" to guide the market. The social significance of the government's macrocontrol is greater than its economic significance, and it should continue to be implemented.

As the paper focuses on the fluctuation of the pig cycle, some model parameters and formulas have not been accurately calibrated, and some feedback are not added to the model. Since the impact of random shocks is not considered, the simulated pig price is smoother than the actual pig price data. Econometrics can be used to estimate parameters more accurately. Besides, further decomposition of the structure of the pig supply chain can make the model results closer to actual data.

\section{Data Availability}

The data used to support the findings of this study are included within the article.

\section{Conflicts of Interest}

The authors declare that they have no conflicts of interest.

\section{Acknowledgments}

This research was supported by the National Natural Science Foundation of China (G010303).

\section{References}

[1] R. H. Coase and R. F. Fowler, "Bacon production and the pigcycle in Great Britain," Economica, vol. 2, no. 6, pp. 142-167, 1935.

[2] R. H. Coase and R. F. Fowler, "The pig-cycle in Great Britain: an explanation," Economica, vol. 4, no. 13, p. 55, 1937.

[3] L. D. Stearns and L. A. Petry, "Hog market cycles", library.ndsu.edu, 1996.

[4] P. J. Dawson, "The UK pig cycle: a spectral analysis," British Food Journal, vol. 111, no. 11, pp. 1237-1247, 2009.

[5] J. D. Sterman, Business Dynamics Systems Thinking and Modeling for a Complex World, McGraw-Hill Higher Education, New York, NY, USA, 2000.

[6] M. H. Huang, "International comparisons of cattle cycles," American Journal of Agricultural Economics, vol. 78, no. 4, pp. 855-868, 1996.

[7] M. Ezekiel, “The cobweb theorem," The Quarterly Journal of Economics, vol. 52, no. 2, pp. 255-280, 1938.

[8] A. A. Harlow, "The hog cycle and the cobweb theorem," American Journal of Agricultural Economics, vol. 42, no. 2, pp. 842-853, 1960.

[9] H. Talpaz, "Multi-frequency cobweb model: decomposition of the hog cycle," American Journal of Agricultural Economics, vol. 56, no. 1, pp. 38-49, 1974.

[10] F. V. Waugh, "Cobweb models," Journal of Farm Economics, vol. 46, no. 4, pp. 732-750, 1964.

[11] L. D. McClements, "Econometric forecasts of pig supply," Applied Economics, vol. 2, no. 1, pp. 27-34, 1970.

[12] M. E. Slade, "Trends in natural-resource commodity prices: an analysis of the time domain," Journal of Environmental Economics and Management, vol. 9, no. 2, pp. 0-137, 1982.

[13] G. C. Haas and M. Ezekiel, Factors Affecting the Price of Hogs, U.S. Department of Agriculture, Washington, DC, USA, 1926.

[14] H. A. Simon, Models of Bounded Rationality, The MIT Press, Cambridge, MA, USA, 1982.

[15] E. Berg and R. Huffaker, "What drives the German hog price cycle? diagnostic modeling of a nonlinear dynamic system," in Proceedings of the EAAE 2014 Congress Agri-Food and Rural Innovations for Healthier Societies, Ljubljana, Slovenia, August 2014.

[16] A. Tversky and D. Kahneman, "Judgment under uncertainty: heuristics and biases," Science, vol. 185, pp. 1124-1131, 1974.

[17] D. A. Bessler and J. A. Brandt, "Forecasting livestock prices with individual and composite methods," Applied Economics, vol. 13, no. 4, pp. 513-522, 1981.

[18] Rostow, W. (1993) Nonlinear dynamics and economics: A Historian's Perspective, in Day.

[19] D. Kahneman and A. Tversky, "The simulation heuristic," "The simulation heuristic," in Judgment under Uncertainty: Heuristics and Biases, D. Kahneman, Ed., Cambridge University Press, Cambridge, UK, 1982.

[20] M. Nerlove, "Adaptive expectations and cobweb phenomena," The Quarterly Journal of Economics, vol. 72, no. 2, pp. 227240, 1958. 
[21] A. Marcet and T. J. Sargent, "The fate of systems with "adaptive" expectations," American Economic Review, vol. 78, no. 2, pp. 168-172, 1988.

[22] M. E. Gerlow, S. H. Irwin, and T.-R. Liu, "Economic evaluation of commodity price forecasting models," International Journal of Forecasting, vol. 9, no. 3, pp. 387-397, 1993.

[23] Y. Tan and H. O. Zapata, "Southern, hog price transmission in Global markets: China EU and U.S." in Proceedings of the Agricultural Economics Association 2014 Annual Meeting, Dallas, TX, USA, February 2014.

[24] H. F. Breimyer, "Emerging phenomenon: a cycle in hogs," Journal of Farm Economics, vol. 41, no. 4, p. 760, 1959.

[25] W. Shun, S. Liming, and J. Zeng, "An empirical analysis of the influencing factors of pork price volatility in my country," Cooperative Economy and Technology, vol. 578, no. 3, pp. 82-85, 2018.

[26] R. T. Norris, The Theory of Consumer's Demand, Ph.D. thesis, Yale University Press, New Haven, CT, USA, 1941.

[27] Y. Qi, Study on Price Fluctuation in China's Pig Market, Shenyang Agricultural University, Shenyang, China, 2008.

[28] S. He, H. Zeng, and B. He, "Estimation and periodic comparison of pork demand elasticity of rural residents in Chinabased on extended linear expenditure system," Jiangsu Agricultural Sciences, vol. 45, no. 15, pp. 335-338, 2017.

[29] R. A. Heiner, The American Economic Review, American Economic Association, vol. 73, no. 4, pp. 560-595, Nashville, TN, USA, 1983.

[30] J. M. E. Pennings and A. Smidts, "Assessing the construct validity of risk attitude," Management Science, vol. 46, no. 10, pp. 1337-1348, 2000.

[31] D. Kahneman, "Experienced utility and objective happiness: a moment-based approach," Choices, Values, and Frames, vol. 39, pp. 673-692, 2000.

[32] L. H. Bean, "The farmers' response to price," Journal of Farm Economics, vol. 11, no. 3, pp. 368-385, 1929.

[33] C. R. E. Bailey, "A Theory of commodity price fluctuations," Journal of Political Economy, vol. 104, no. 5, pp. 924-957, 1996.

[34] D. J. Hayes and A. Schmitz, "Hog cycles and countercyclical production response," American Journal of Agricultural Economics, vol. 69, no. 4, pp. 762-770, 1987.

[35] Y. He and X. Zhao, "Coordination in multi-echelon supply chain under supply and demand uncertainty," International Journal of Production Economics, vol. 139, no. 1, pp. 106-115, 2012.

[36] Y. He and X. Zhao, "Contracts and coordination: supply chains with uncertain demand and supply," Naval Research Logistics (NRL), vol. 63, no. 4, pp. 305-319, 2016.

[37] N. M. Modak and P. Kelle, "Using social work donation as a tool of corporate social responsibility in a closed-loop supply chain considering carbon emissions tax and demand uncertainty," Journal of the Operational Research Society, 2019.

[38] N. M. Modak, N. Modak, S. Panda, and S. S. Sana, “Analyzing structure of two-echelon closed-loop supply chain for pricing, quality and recycling management," Journal of Cleaner Production, vol. 171, pp. 512-528, 2018.

[39] N. M. Modak and P. Kelle, "Managing a dual-channel supply chain under price and delivery-time dependent stochastic demand," European Journal of Operational Research, vol. 272, no. 1, pp. 147-161, 2019.

[40] P. He, H. Y. He, and H. Xu, "Channel structure and pricing in a dual-channel closed-loop supply chain with government subsidy," International Journal of Production Economics, vol. 213, pp. 108-123, 2019.
[41] S. S. Sana, N. M. S. Panda, and N. Modak, "Optimal replenishment and sales team initiatives for pharmaceutical products - a mathematical model," Pacific Science Review B: Humanities and Social Sciences, vol. 1, no. 1, pp. 15-21, 2015.

[42] Y. He, D. H. Huang, S. J. C. Li, C. Shi, and S. Wu, "Quality and operations management in food supply chains: a literature review," Journal of Food Quality, vol. 2018, Article ID 7279491, 14 pages, 2018.

[43] M. T. Holt and L. A. Craig, "Nonlinear dynamics and structural change in the U.S. Hog-corn cycle: a time-varying STAR approach," American Journal of Agricultural Economics, vol. 88, no. 1, pp. 215-233, 2006.

[44] D. Zhou and D. Koemle, "Price transmission in hog and feed markets of China," Journal of Integrative Agriculture, vol. 14, no. 6, pp. 1122-1129, 2015.

[45] D. L. Meadows, Dynamics of Commodity Production Cycles, Pegasus Communications, Waltham, MA, USA, 1970.

[46] J. A. Schumpeter, A Theory of Economic Development, pp. 61-116, Bloomsbury Business Library Management Library, London, UK, 1934.

[47] J. Sterman, Handbook of Behavioral Operations Management: Social and Psychological Dynamics in Production and Service Settings, E. Bendoly, W. van Wezel, and D. Bachrach, Eds., pp. 203-237, Oxford University Press, New York, NY, USA, 2015. 